\title{
Study on the Cause of Car Accidents at Intersections
}

\author{
Fan Fan \\ Shanghai University of Engineering Science (SUES), Shanghai, China \\ Email: fanxiaojiu1990@163.com
}

How to cite this paper: Fan, F. (2018) Study on the Cause of Car Accidents at Intersections. Open Access Library Journal, 5: e4578.

https://doi.org/10.4236/oalib.1104578

Received: April 5, 2018

Accepted: May 8, 2018

Published: May 11, 2018

Copyright (c) 2018 by author and Open Access Library Inc.

This work is licensed under the Creative Commons Attribution International License (CC BY 4.0).

http://creativecommons.org/licenses/by/4.0/

\section{(c) (†) Open Access}

\begin{abstract}
The accident data used in this paper are all collected from the traffic accident investigation team of Shanghai University of Engineering Science from 2008 to 2017. The analysis is based on full and detailed data. The conclusion can provide a reliable basis for the prevention of car accidents in domestic intersections. The content of this paper can be summarized as follows: The fault tree analysis method is used to analyze the traffic accident data collected and explore the deeper causes of interjunction accidents. The logical relationship between the occurrence of the intersection car accident and the factors such as human, car, road and environment is summarized from the top down to the fault tree model. Finally, the model is qualitatively analyzed and the mechanism of the accident is deduced systematically. Research shows: Drivers do not avoid or avoid effective collision for vehicles that are going to collide, which are the two basic events that cause the collision of cars at the crossroads.
\end{abstract}

\section{Subject Areas}

Mineral Engineering

\section{Keywords}

Traffic Safety, The Intersection of Traffic Accidents, Fault Tree, Accident Causation

\section{Introduction}

The intersections converge in all directions and are at the heart of the whole road traffic system. The prevention and control of intersection accidents and the safety of road environment have become the theme of traffic accident safety research [1]. In order to deal with the safety of traffic safety and vehicle safety of intersections, it is necessary to analyze the accident data in the intersection. 
FTA (Fault Tree Analysis) is a method of evaluating the reliability and security of the whole system by building a special tree like logic diagram from top to bottom [2]. The fault tree analysis method shows "how the system is malfunction" in the form of a tree graph (using a given event, logical gate and other basic connection symbols to express the logical relationship between the various events in the whole system). For logic gates, input events are the reasons for output events, while output events are the result of input events. The fault tree defines the selected system failure state as the top event. By analyzing the reasons that may cause system failure, we reveal the logical relationship between the failure of each component (module) and the system failure. Therefore, the method has a clear and clear understanding of the possible existence of the whole system failure [3]. It can fully point out the shortcomings of the system, and can reflect the fault probability calculation system, which can be used to evaluate the components of each module in the fault tree [4].

\section{Theoretical Background of Cumulative Logistic Regression}

The fundamental purpose of fault tree construction is to describe the state or environment of accident when it is built. For the establishment of car accident fault tree at intersection, we must have a comprehensive understanding of the system to be analyzed, including people, cars, roads and environment. The main contents are as follows:

1) how did car accidents happen at intersections?

2) how to express the connection between failure events by function relation.

3) how to excavate the driver's human factors in the accident.

4) how to excavate the mechanism of car failure.

5) grasp the information of road environment [5].

Take the accident at a crossroad as the top event. Taking "driver's compliance with traffic rules" as the first branch, it is related to the top event of "traffic accident at a crossroad". The branch on the left side of the first stage is "collision when the driver obeys the traffic rules", which is caused by the driver's decision errors or operational errors. Kuzminski put forward the concept of "four driver subsystems" in 1995, including: perception, understanding, decision making and action. Sensing system: collecting information from environment and vehicle. Understanding system: correctly understanding information from its own perception system. Decision system: Based on the understanding of traffic condition, maintain the specific operation condition of vehicle. Action system: make a subjective decision [6].

In this chapter, a "driver subsystem" is extended on the basis of the "four driver subsystem" of Kuzminski, to explore that not all the factors involved in traffic conditions are controlled by the driver. Besides, in the research of this chapter, the perception system and understanding system are brought into the decision system to simplify the analysis [7]. The decision system is redefined as the ability of drivers to perceive, understand and make the right decisions. When 
the driver's driving behavior is considered to obey the traffic rules, the factors that affect the car accident at the intersection are the driver's decision error or the misoperation of the driver (Figure 1).

The first grade right-hand branch is "when the driver does not obey the traffic rules", it is a result of the driver's physiological or mental state.

Wherever Times is specified, Times Roman or Times New Roman may be used. If neither is available on your word processor, please use the font closest in appearance to Times. Avoid using bit-mapped fonts if possible. True-Type 1 or Open Type fonts are preferred. Please embed symbol fonts, as well, for math, etc.

As shown in Figure 2, the driver makes the wrong decision when the collision caused by a decision error occurs when the track of the car overlaps with the other vehicles' track or the fixtures. "Wrong decision" refers to the error of the driver's instructions to the execution of the vehicle, which can be divided into two cases, "human error" and "vehicle self defect". "Vehicle running track" means that cars and other collision objects overlap in time and space, and the collision is unavoidable and there is no successful circumvention operation.

As shown in Figure 3, "the collision caused by improper operation" is due to the improper operation of drivers, resulting in overlapping trajectories of collision objects. The "wrong operation" means that the driver failed to execute the operation that might prevent the accident. The misoperation of the car is usually caused by the lack of experience of the driver or unfamiliarity with the driving car. "Human error" and "vehicle self defect" may directly lead to the driver 's "wrong operation". The "vehicle running track" is consistent with the above definition. "Human error" is usually caused by the driver's failure to get the ability to drive autonomously or to take full account of the road environment.

As shown in Figure 4, "the collision caused by poor mental condition" is due to the collision caused by excessive anxiety, impatience, or concentration of the driver's mental state.

Figure 5 shows "collision caused by poor physical condition", which is affected by various factors.

\section{Data}

In the qualitative analysis of the fault tree model of the car accident at the intersection, the two methods of minimum cut set and structural importance are used to analyze the model.

The so-called minimum cut set is a set of basic events that can cause the minimum of events on top of the top, that is to say, if any basic event does not occur in the cut centralization, the top event will not occur. The minimum cut set can also represent the risk of the system. How many minimum cut sets are included in the fault tree, and there are several possibilities for the top event to happen. If the minimum cut set in the fault tree is more, the more the path of the system will happen, the more dangerous the will be. To sum up, the minimum cut set of the fault tree is designed to analyze the combination of the basic events that cause the top events, that is, to find the cause of the event on the top (Table 1). 


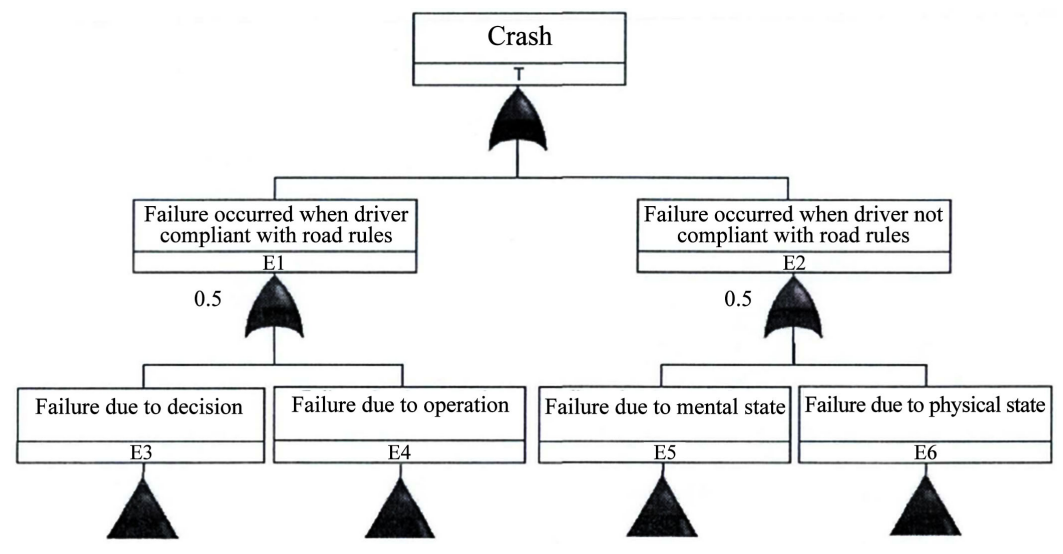

Figure 1. Top-level fault tree.

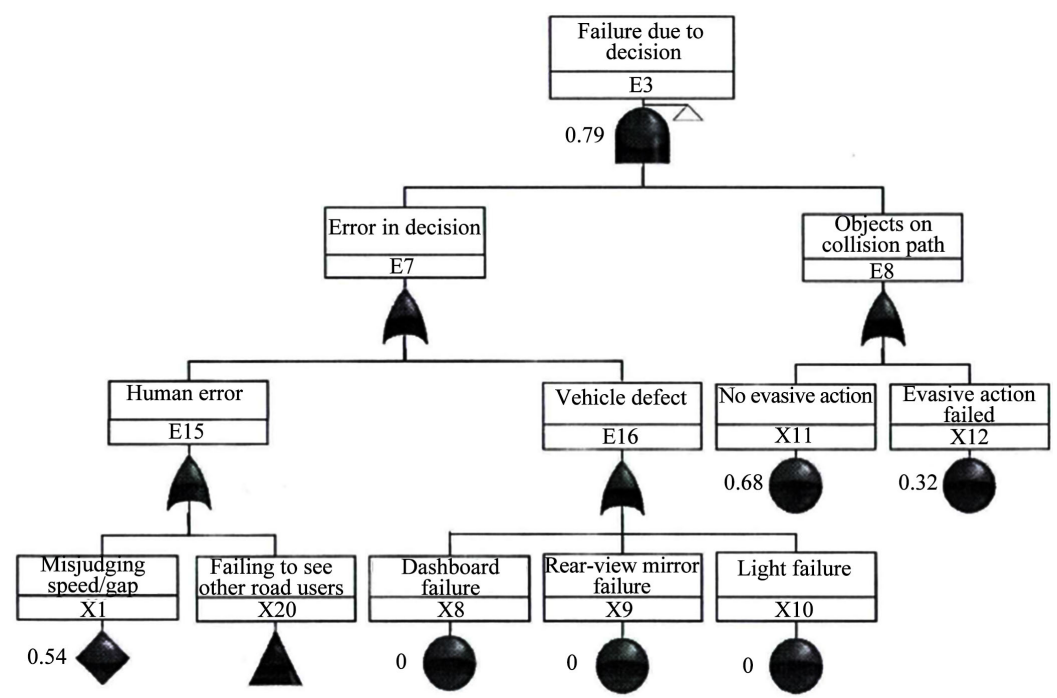

Figure 2. Failure due to decision sub-tree.

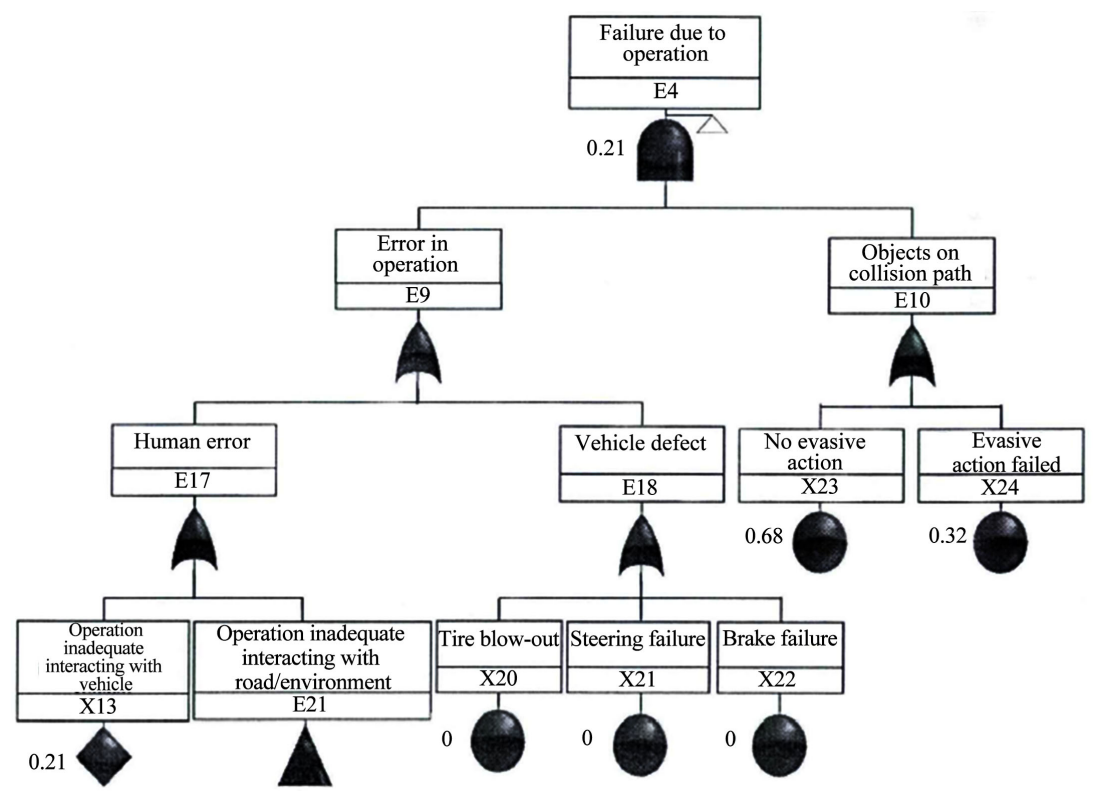

Figure 3. Failure due to operation sub-tree. 


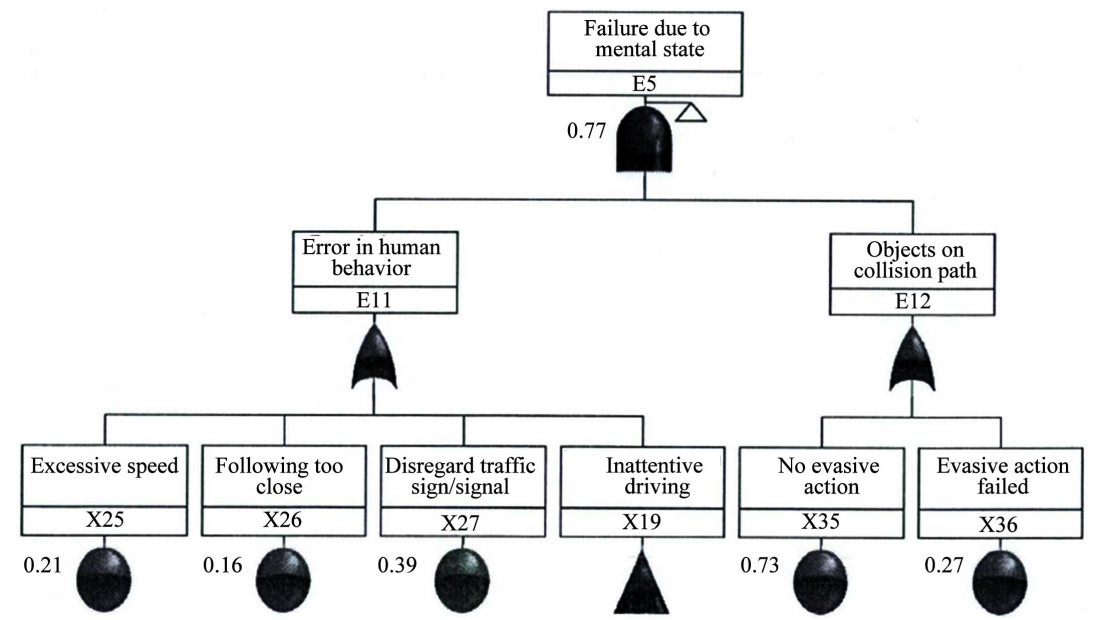

Figure 4. Failure due to mental sub-tree.

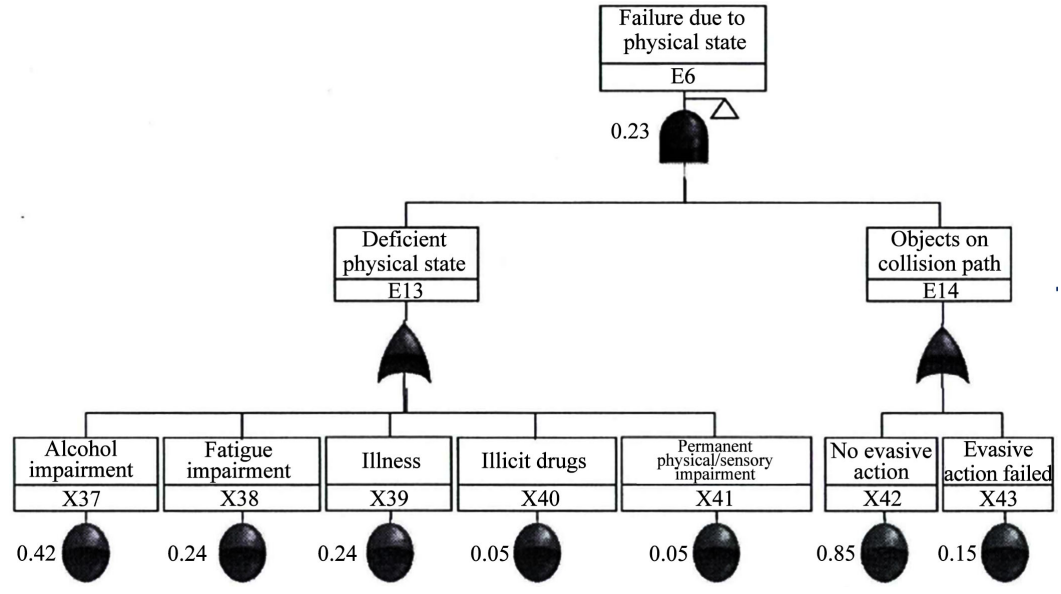

Figure 5. Failure due to physical sub-tree.

Table 1. Minimal cut sets.

\begin{tabular}{cc}
\hline Min cut sets & Events \\
\hline X1, X11 & Misjudging speed/gap, No evasive action \\
X27, X35 & Disregarding traffic sign/signal, No evasive action \\
X1, X12 & Misjudging speed/gap, Evasive action failed \\
X25, X35 & Excessive speeding, No evasive action \\
X37, X42 & Alcohol impairment, No evasive action \\
X5, X7, X11 & Vision obscured by roadside objects, Inadequate lookout, No evasive action \\
X3, X7, X11 & Vision obscured by poor weather, Inadequate lookout, No evasive action \\
X4, X7, X11 & Vision obscured by other vehicles, Inadequate lookout, No evasive action \\
X34, X35 & Mental distraction, No evasive action \\
X38, X42 & Fatigue impairment, No evasive action \\
X39, X42 & Illness, No evasive action \\
X16, X19, X23 & Poor layout, Inexperience, No evasive action \\
X25, X36 & Excessive speeding, Evasive action failed \\
\hline
\end{tabular}


Structural importance degree refers to the degree of probability that a basic event does not take account of the occurrence of basic events.

The occurrence of each basic event has an impact on the top events, but the degree of influence is different. We carry out the analysis of the structural importance, which is to analyze which basic events have a great impact on the top events, which, which are the least affected and sort, so that there is a security precaution. Prioritization, in order to make the system achieve economic, effective and safe purposes. Structural importance analysis is a qualitative analysis of importance, but in the absence of quantitative analysis of data, this analysis is also more important, and the effect of the analysis is obvious.

First, we explore the relationship between $i$ and the top events. If $i$ happens, the opposite happens. At this time, the state vector $\left(1_{t}, x\right)$ is called the dangerous cut vector of the basic event $i$, and the corresponding cut set is called the dangerous cut set. For the basic event $i$, the number of dangerous cutting vectors is $n_{\Phi}(i)$ :

$$
n_{\Phi}(i)=\sum_{x=1}\left[\Phi\left(1_{i}, x\right)-\Phi\left(0_{i}, x\right)\right]
$$

It is known that the more dangerous cut vectors of basic events, the greater the impact of $i$ on top events. Except for the basic event $i$, the rest of the basic events combination number is $2^{n-1}$.

The structural importance of the basic event $i, I_{\Phi}(i)$ is defined as:

$$
I_{\Phi}(i)=\frac{n_{\Phi}(i)}{2^{n-1}}=\frac{\sum_{x=1}\left[\Phi\left(1_{i}, x\right)-\Phi\left(0_{i}, x\right)\right]}{2^{n-1}}
$$

There are two ways to analyze the importance of structure. First, we use the minimum cut set to approximate the structural importance of a basic event. The second way is to find out the structural importance coefficients of basic events by calculating, and then rank these coefficients from large to small in order to arrange basic events.

According to the calculation of structural importance, the structure importance order of various basic events is excluded, and the influence degree of the basic events on the top events is understood from the structure of the fault tree model, and the prevention work of the accident is arranged in order of importance to achieve the purpose of scientific prevention.

The probability of each basic event in the car accident fault tree model established at this intersection cannot be determined, so the model is not quantitatively analyzed (Table 2).

\section{Results and Interpretations}

\subsection{Results}

Through the qualitative analysis of the fault tree model of the car accident at the intersection, the calculation results of the minimum cut set and the structure importance can be obtained, and several aspects of the cause of the car accident 
Table 2. The structure of each basic event importance.

\begin{tabular}{|c|c|}
\hline Serial number & Structural importance \\
\hline \multirow{2}{*}{1} & $\mathrm{X} 36, \mathrm{X} 35$ \\
\hline & $\mathrm{I}(\mathrm{X} 36)=\mathrm{I}(\mathrm{X} 35)=0.133$ \\
\hline \multirow{2}{*}{2} & $\mathrm{X} 43, \mathrm{X} 42$ \\
\hline & $\mathrm{I}(\mathrm{X} 43)=\mathrm{I}(\mathrm{X} 42)=0.077$ \\
\hline \multirow{2}{*}{3} & $\mathrm{X} 24, \mathrm{X} 23, \mathrm{X} 12, \mathrm{X} 11$ \\
\hline & $\mathrm{I}(\mathrm{X} 24)=\mathrm{I}(\mathrm{X} 23)=\mathrm{I}(\mathrm{X} 12)=\mathrm{I}(\mathrm{X} 11)=0.061$ \\
\hline \multirow{2}{*}{4} & $\mathrm{X} 22, \mathrm{X} 21, \mathrm{X} 20, \mathrm{X} 13, \mathrm{X} 10, \mathrm{X} 9, \mathrm{X} 8, \mathrm{X} 1$ \\
\hline & $\mathrm{I}(\mathrm{X} 22)=\mathrm{I}(\mathrm{X} 21)=\mathrm{I}(\mathrm{X} 20)=\mathrm{I}(\mathrm{X} 13)=\mathrm{I}(\mathrm{X} 10)=\mathrm{I}(\mathrm{X} 9)=\mathrm{I}(\mathrm{X} 8)=\mathrm{I}(\mathrm{X} 1)=0.043$ \\
\hline \multirow{2}{*}{5} & $\mathrm{X} 41, \mathrm{X} 40, \mathrm{X} 39, \mathrm{X} 38, \mathrm{X} 37$ \\
\hline & $\mathrm{I}(\mathrm{X} 41)=\mathrm{I}(\mathrm{X} 40)=\mathrm{I}(\mathrm{X} 39)=\mathrm{I}(\mathrm{X} 38)=\mathrm{I}(\mathrm{X} 37)=0.039$ \\
\hline \multirow{2}{*}{6} & $\mathrm{X} 19, \mathrm{X} 7$ \\
\hline & $\mathrm{I}(\mathrm{X} 19)=\mathrm{I}(\mathrm{X} 7)=0.025$ \\
\hline \multirow[b]{2}{*}{7} & $\mathrm{X} 18, \mathrm{X} 17, \mathrm{X} 16, \mathrm{X} 15, \mathrm{X} 14, \mathrm{X} 6, \mathrm{X} 5, \mathrm{X} 4, \mathrm{X} 3, \mathrm{X} 2$ \\
\hline & $\begin{array}{c}\mathrm{I}(\mathrm{X} 18)=\mathrm{I}(\mathrm{X} 17)=\mathrm{I}(\mathrm{X} 16)=\mathrm{I}(\mathrm{X} 15)=\mathrm{I}(\mathrm{X} 14)=\mathrm{I}(\mathrm{X} 6)=\mathrm{I}(\mathrm{X} 5)=\mathrm{I}(\mathrm{X} 4)=\mathrm{I}(\mathrm{X} 3)= \\
\mathrm{I}(\mathrm{X} 2)=0.019\end{array}$ \\
\hline \multirow[b]{2}{*}{8} & $\mathrm{X} 34, \mathrm{X} 33, \mathrm{X} 32, \mathrm{X} 31, \mathrm{X} 30, \mathrm{X} 29, \mathrm{X} 28, \mathrm{X} 27, \mathrm{X} 26, \mathrm{X} 25$ \\
\hline & $\begin{array}{c}\mathrm{I}(\mathrm{X} 34)=\mathrm{I}(\mathrm{X} 33)=\mathrm{I}(\mathrm{X} 32)=\mathrm{I}(\mathrm{X} 31)=\mathrm{I}(\mathrm{X} 30)=\mathrm{I}(\mathrm{X} 29)=\mathrm{I}(\mathrm{X} 28)=\mathrm{I}(\mathrm{X} 27)=\mathrm{I} \\
(\mathrm{X} 26)=\mathrm{I}(\mathrm{X} 25)=0.014\end{array}$ \\
\hline \multicolumn{2}{|c|}{$\begin{array}{l}\text { The order of structural importance is: } \mathrm{I}(\mathrm{X} 36)=\mathrm{I}(\mathrm{X} 35)>\mathrm{I}(\mathrm{X} 43)=\mathrm{I}(\mathrm{X} 42)>\mathrm{I}(\mathrm{X} 24)=\mathrm{I}(\mathrm{X} 23)=\mathrm{I}(\mathrm{X} 12)=\mathrm{I} \\
(\mathrm{X} 11)>\mathrm{I}(\mathrm{X} 22)=\mathrm{I}(\mathrm{X} 21)=\mathrm{I}(\mathrm{X} 20)=\mathrm{I}(\mathrm{X} 13)=\mathrm{I}(\mathrm{X} 10)=\mathrm{I}(\mathrm{X} 9)=\mathrm{I}(\mathrm{X} 8)=\mathrm{I}(\mathrm{X} 1)>\mathrm{I}(\mathrm{X} 41)=\mathrm{I}(\mathrm{X} 40)=\mathrm{I} \\
(\mathrm{X} 39)=\mathrm{I}(\mathrm{X} 38)=\mathrm{I}(\mathrm{X} 37)>\mathrm{I}(\mathrm{X} 19)=\mathrm{I}(\mathrm{X} 7)>\mathrm{I}(\mathrm{X} 18)=\mathrm{I}(\mathrm{X} 17)=\mathrm{I}(\mathrm{X} 16)=\mathrm{I}(\mathrm{X} 15)=\mathrm{I}(\mathrm{X} 14)=\mathrm{I}(\mathrm{X} 6)=\mathrm{I} \\
(\mathrm{X} 5)=\mathrm{I}(\mathrm{X} 4)=\mathrm{I}(\mathrm{X} 3)=\mathrm{I}(\mathrm{X} 2)>\mathrm{I}(\mathrm{X} 34)=\mathrm{I}(\mathrm{X} 33)=\mathrm{I}(\mathrm{X} 32)=\mathrm{I}(\mathrm{X} 31)=\mathrm{I}(\mathrm{X} 30)=\mathrm{I}(\mathrm{X} 29)=\mathrm{I}(\mathrm{X} 28)=\mathrm{I} \\
(\mathrm{X} 27)=\mathrm{I}(\mathrm{X} 26)=\mathrm{I}(\mathrm{X} 25) .\end{array}$} \\
\hline
\end{tabular}

at the intersection can be obtained.

1) from the structural importance obtained, it is known that the driver's unavoided or uneffective avoidance of the impending vehicle is the two basic event that causes the biggest impact of the collision at the intersection, and the driver does not avoid the impending collision in the case of poor mental state and physiological state. The degree of the impact of effective avoidance is greater than that of a driver in the case of decision-making errors and improper operation.

2) in the vehicle factors, the car brakes failure, the steering system failure, the tire burst, the car light failure, the rear view mirror fault and other adverse factors are combined with the driver's unavoided or uneffective avoidance factors, which can easily lead to the occurrence of car accidents at the intersection.

3 ) in the human factors, the driver's physiological factors such as alcohol driving, fatigue driving, drug effect and other factors such as driver's driving experience and attention are not the main causes of car accidents at intersection, but not the main cause of the accident, and the number of accidents in this kind of situation is relatively small.

4) in the road environment factors, the unsuitable speed limit of road, the control factor of traffic signal, the layout of road design, the condition of road show, the weather condition and the fault of the street lamp are also the im- 
portant factors that cause the accident of the car at the intersection. Such factors are mainly affected by the driver's sight, the vehicle's own stability and other factors, when these factors usually induce the accident in the intersection with the driver's lack of driving experience and the concentration of the driver's attention.

5) when the driver's mental condition is not good, when the vehicle over speed, the safety distance of the workshop is insufficient, the driver ignores the traffic signs and traffic signal lights, the driver is disturbed by other passengers and other factors, the accident will occur when the driver is not allowed to avoid or avoid the effective avoidance. But the impact of such factors on vehicles is relatively small.

\subsection{Discussions}

On the basis of the accident cause analysis based on the fault tree based intersection, the accident data and design data of this section are analyzed and studied in detail on the basis of the analysis of the intersection of the intersection in Shanghai, and the accident reduction of the intersection is analyzed and studied.

The frequent occurrence of the accident is a typical accident prone intersection. According to incomplete statistics, there were more than 9 car crash accidents happened here in 2017. Among them, 5 accidents occur at night, and the driver's line of sight will be affected to a certain extent; the speed limit of the intersection is $40 \mathrm{~km} / \mathrm{h}$, and the speed of the accident occurs more than $40 \mathrm{~km} / \mathrm{h}$ according to the driver's record and the result of the accident reconstruction.

Figure 6 is the aerial picture of the intersection. The road information is: the road width of the east-west direction is $16.5 \mathrm{~m}$, the two-way two lane, the two direction lane is isolated by the single yellow dotted line, the motorized lane and the non motorized lane are isolated by the white line; the road width of the North-South direction is $6.2 \mathrm{~m}$, the bidirectional two lane, the two lane no isolation and no road at the intersection. Traffic signs, the upstream speed limit signs, no road lights at the intersection, the intersection speed limit is $40 \mathrm{~km} / \mathrm{h}$. The North-South Road near the intersection section is the upper slope section, and the speed of driving on the upper slope is more difficult to control, thus causing adverse accident factors.

Through the establishment of an accident fault tree model of the intersection car, it can be found that the combination of unfavorable factors will lead to the occurrence of the accident, and the importance of the adverse factors in the accident, and the improvement suggestions on the improvement of the traffic facilities at the multiple junctions of the accident are put forward.

Most of the accidents are caused by over speed. In the case of no change in the line shape of the road, it is the key to improve the deceleration efficiency of the traffic facilities at this intersection. Therefore, we can increase the speed limit sign at the intersection, and add a vibration deceleration marking line near the intersection. 
On the basis of the above, we can also use the principle of illusion, and use the method shown in Figure 7 at the distance from the intersection to make the driver feel the lane narrowing in front of the vision, so as to achieve the goal of reducing speed.

The collision type of the car accident at this intersection is mainly caused by the collision between turning vehicles and the head-on workshop. The collision barrier can be set in the two section of the road near the intersection, which can not only avoid the opposite collision but also reduce the severity of the accident.

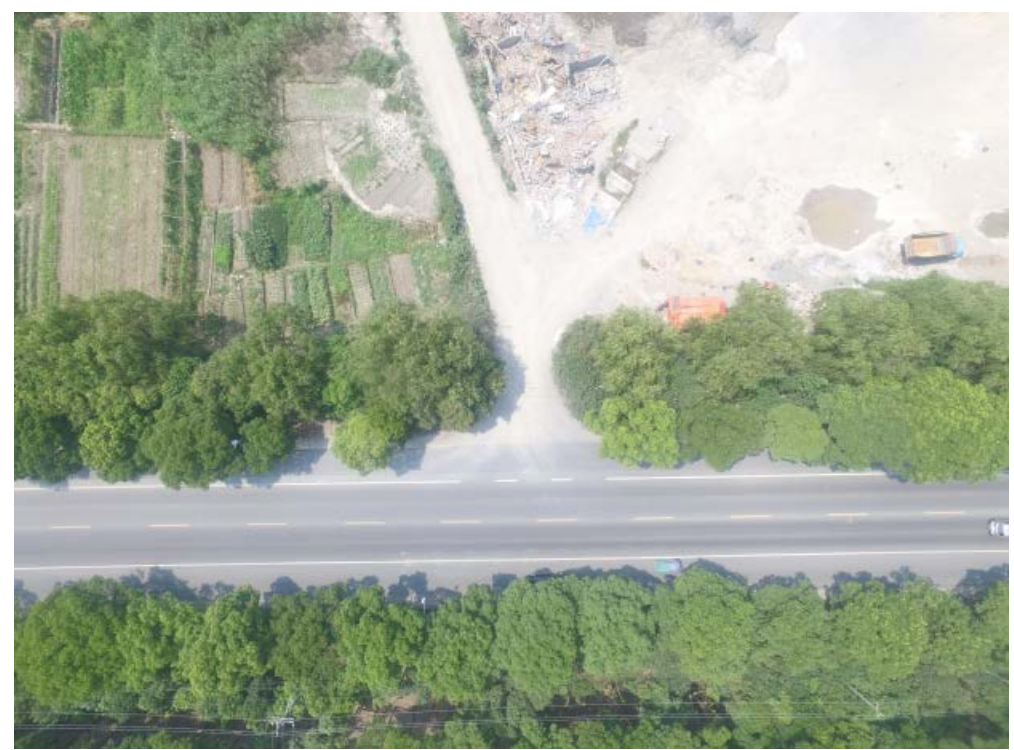

Figure 6. The aerial view of the intersection.
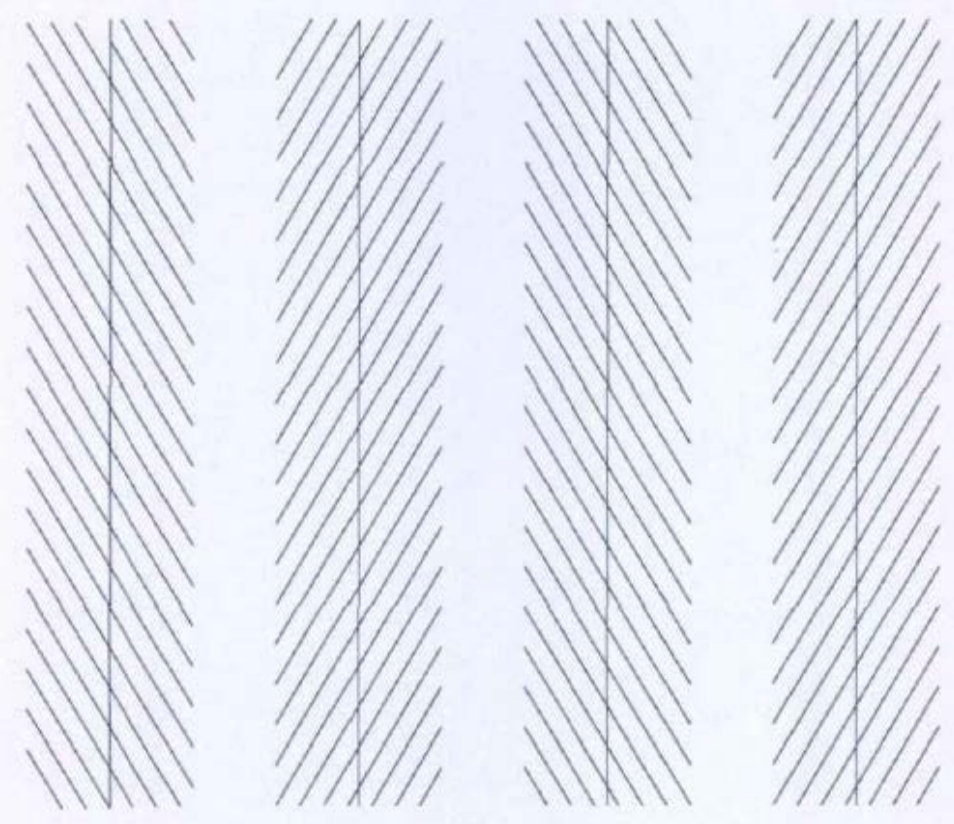

Figure 7. Schematic of the principle of illusion. 


\section{Conclusions}

The accident model based on the fault tree is set up, the accident model is analyzed qualitatively, and the model results are summarized from the aspects of human, car and road environment. It is concluded that the driver's failure to avoid or avoid the effective avoidance of the impending vehicle is the most impact on the collision. In the vehicle factors, the car brakes failure, the steering system failure, the tire burst, the car light failure, the rear view mirror fault and other adverse factors are combined with the driver's unavoided or uneffective avoidance factors, which can easily lead to the occurrence of car accidents at the intersection.

In the driver's factors, the driver's physiological factors such as alcohol driving, fatigue driving, drug effect and other factors such as driver's driving experience and attention are not the main causes of car accidents at the intersection, but not the main cause of the accident; in the road environment factors, the road speed limit is improper, traffic Signal control factors, road design layout, road indication, weather condition, road lamp failure are also important factors that lead to car accidents at intersection, and drivers are overlooking the traffic signs and traffic signals, drivers are interfered by other passengers and other factors when the vehicle is over speed, and the driver is disturbed by other passengers. No accident avoidance or no effective avoidance will lead to the occurrence of intersection accidents. But the impact of such factors on vehicles is relatively small.

Select the accident multiple intersection as the analysis object, use the result of the set up fault tree model to carry on the pertinence analysis, find out the inner reason of the accident, and give the improvement suggestion of the accident multiple intersection. This paper summarizes some common safety hazards existing at Songjiang District intersection in Shanghai, and gives some suggestions for improvement.

\section{References}

[1] Layout, A.H. (1995) Design and Operation of a Safe Automated Highway System. PATH/ITS, University of California, Berkeley.

[2] Leveson, N.G. (1997) Safety Analysis of Automated Highway Systems. University of Washington.

[3] Kuhnert, P.M., Do, K. and McClure, R. (2000) Combining Non-Parametric Models with Logistic Regression: An Application to Motor Vehicle Injury Data. Computational Statistics and Data Analysis, 34, 371-386. https://doi.org/10.1016/S0167-9473(99)00099-7

[4] Ozbay, K. and Noyan, N. (2006) Estimation of Incident Clearance Times Using Bayesian. Accident Analysis and Prevention, 38, 542-555.

https://doi.org/10.1016/j.aap.2005.11.012

[5] Mujalli, R.O. and De Ona, J. (2011) A Method for Simplifying the Analysis of Traffic Accidents Injury Severity on Two-Lane Highways Using Bayesian Networks. Journal of Safety Research, 42, 17-326. 
[6] Kuzminski, P., Eisele, J.S., Garber, N., et al. (1995) Improvement of Highway Safety I: Identification of Causal Factors through Fault-Tree Modelling. Risk Analysis, 15, 293-312. https://doi.org/10.1111/j.1539-6924.1995.tb00323.x

[7] Wei, C.R., Sun, J.H. and Zhang, J.P. (2009) Jualitative Fault Tree Analysis and It's Application in Safety Assessment of Mines. Industrial Safety and Enviromental Protection, No. 9. 